\title{
Refining the short version of the Leadership Scale for Sports: factorial validation and measurement invariance
}

Pedro Teques

Carlos Silva

António Rosado

Luis Calmeiro

Sidónio Serpa

Teques, P., Silva, C., Rosado, A., Calmeiro, L., \& Serpa, S. (2020). 'Refining the short version of the Leadership Scale for Sports: factorial validation and measurement invariance'. Psychological Reports.

DOI: https://doi.org/10.1177/0033294120953560

(c) the authors 2020

\section{Information for Users of the Institutional Repository}

Users who receive access to an article through a repository are reminded that the article is protected by copyright and reuse is restricted to non-commercial and no derivative uses. Users may also download and save a local copy of an article accessed in an institutional repository for the user's personal reference. For permission to reuse an article, please follow our Process for Requesting Permission. 
Running head: LSS SHORT-VERSION

Refining the short version of the Leadership Scale for Sports: Factorial validation and measurement invariance 
1

4 Chelladurai \& Saleh, 1980): coaches' perceptions of their own behavior, athletes'

5 preferences and athletes' perceptions of their coaches' behavior. This validation will

6 allow researchers to minimize time demands on participants. Three independent samples

7 of athletes $\left(n_{1}=373 ; n_{2}=817 ; n_{3}=246\right)$ and two samples of coaches $\left(n_{1}=115 ; n_{2}=351\right)$

8 were studied to examine the factorial validity and measurement invariance of the 25 -item

9 version of the LSS (LSS-25; Chiu et al., 2016). Findings indicated that a 15-item version

\section{Abstract}

The purpose of this investigation was to examine the factorial validity and measurement invariance of the short version of the Leadership Scale for Sports (LSS; (LSS-15) fits the data better than the LSS-25. The LSS-15 showed factorial validity and proved to have adequate reliability, convergent validity and discriminant validity. Multiple-group confirmatory factor analysis showed that its factor structure was invariant across two independent samples and across gender for athletes' perceived and preferred versions. Significant relationships between the LSS-15 subscales and athlete satisfaction also demonstrate criterion validity. These findings support a valid and reliable alternative to the original LSS long-form, especially in applied settings when time constraints require a brief measure of leadership or when study designs include multiple variables.

Keywords: confirmatory factor analysis, factorial validity, leadership, multi-group factor analysis, reliability. 
Refining the short version of the Leadership Scale for Sports: Factorial validation and measurement invariance

The aim of this investigation is to test the factorial validity and measurement invariance of a short version of the Leadership Scale for Sports (LSS; Chelladurai \& Saleh, 1980) across two independent samples and across gender. Acknowledged as a leading multidimensional leadership measurement instrument (Chelladurai, 2007; Chelladurai, \& Riemer, 1998), the original 40-item LSS is composed of three versions, which evaluate the coaches' perceptions of their own behavior, the athletes' preferences of their coaches' behavior and the athletes' perceptions of their coaches' behavior. Each version define five leadership constructs and is composed by 40 items making the LSS a lengthy instrument to be utilized in practice and applied research (see Appendix). To avoid this constraint, recently Chiu, Rodriguez, and Won (2016) validated a short 25-item version (LSS-25) using exploratory structural equation modeling. This was an important contribution to the literature as in many scenarios the use of the full 40 -item measures may not be feasible. An LSS short version may be beneficial in applied settings because it reduces the time required for participants to complete the instrument or the total number of items needed to test models that include several variables.

Despite the valuable contributions of the 25-item LSS (Chiu et al., 2016), the psychometric development of a scale is an ongoing process. Indeed, Chiu et al. highlighted the relevance of future studies to validate the short version across independent 
samples and in different genders. Measurement invariance analysis is important for the psychometric development of an instrument as it allows researchers to make suitable comparisons of the data across groups (e.g., gender) (Marsh, Ellis, Parada, Richards, \& Heubeck, 2005). Additionally, Chiu et al. examined only the athletes' perceived version of LSS (see Appendix for a description of Chiu et al.'s 25-item LSS). Thus, the present study expands the initial development of the LSS-25 by examining the factorial validity and measurement invariance across gender of the three LSS versions: coaches' perceptions of their own behavior and athletes' preferences and perceptions of their coaches' behavior.

\section{The multidimensional model of leadership}

Chelladurai's multidimensional model of leadership provides a framework for understanding leadership effectiveness in sports (Chelladurai, \& Saleh, 1980; Chelladurai \& Carron, 1983; Chelladurai, 1993, 2007). It contains three domains of the leader's behaviors - required, preferred, and actual - and suggests that leadership effectiveness depends on a series of interactions between the characteristics of the leader, characteristics of the group members and situational constraints. According to the authors, behavior occurs in a dynamic context, where antecedent factors, such as leader and member characteristics, will impact actual leader behaviors and member preferences for leadership behaviors. The model stresses the importance of congruence between 
actual, required and preferred behaviors in predicting athletes' satisfaction with their sporting experience and performance.

The 40-item LSS was developed to estimate leadership behavior and examine the hypothesized associations within the Multidimensional Model of Leadership (MML; e.g., Chelladurai \& Saleh, 1980). This model contains five dimensions of leadership behavior: training and instruction, social support, autocratic, democratic, and positive feedback. Originally, Chelladurai and Saleh (1980) suggested that training and instruction (13 items) represents important functions of the coach, such as explaining the techniques and tactics of sport or instructing athletes on how to improve their performance. Social support behavior ( 8 items) is characterized by the actions of the coach that aim at satisfying the psychosocial needs of the athletes by creating a supportive climate amongst team members. The autocratic behavior ( 5 items) and democratic behavior subscales ( 9 items) reflect the decision style of the coach: while the autocratic behavior reflects the coach's reluctance in sharing the decision-making with the athletes, the democratic behavior reflects the coach's openness in sharing those same decisions. Finally, positive feedback behavior (5 items) indicates the coach's competence in rewarding the athletes' efforts and performance.

The psychometric analysis of LSS (Chelladurai \& Riemer, 1998) suggests that internal reliability coefficients vary between .70 and .80 for training and instruction, social support, democratic, and positive feedback behavior subscales. In contrast, internal 
reliability coefficients below the acceptable value of .70 (Nunnally \& Bernstein, 1994) were found in some subscales (e.g., Kwon, Koh, Pyun, \& Wang, 2009; Kwon, Pyun, Han, \& Ogasawara, 2011). These internal reliability coefficients have been higher for the athletes' perception versions of the LSS, in comparison to the coaches' self-perception and athletes' preference versions of the LSS across various studies.

Considering construct validity, studies using confirmatory factor analysis (e.g., Chelladurai \& Riemer, 1998; Fletcher \& Roberts, 2013) have found support for the 5factor structure of the LSS. Specifically, Chelladurai and Riemer (1998) demonstrated that the hypothesized structure of both perceived and preferred versions of the LSS in young athletes had a good model fit (RMSEA $=.060$ and .062 , respectively). However, other indices were less than adequate (e.g., TLI $=.83$ and .77 ). Other researchers (e.g., Fletcher \& Roberts, 2013; Kwon et al., 2009) reported lower values than the recommended thresholds for TLI and CFI $(<.90)$ and RMSEA $(>.08)$ indices in the perception version of the LSS. Additionally, Fletcher and Roberts (2013) found partial longitudinal invariance for the 5-factor structure across four time periods, and Kwon et al. (2009) reported unsuitable convergent validity, based on factor loadings lower than the cutoff value of .50 .

Taken together, this pattern of results suggests a low fit of the factorial structure of the LSS. Thus, we followed recommendations within the recent literature that support the use of more sophisticated approaches combining hierarchical relationships between 
variables, analysis of measurement models, and larger samples to test the five-factor model of the LSS (Chiu et al., 2016; Fletcher \& Roberts, 2013).

\section{The present research}

This research was designed to examine a short form of the three Leadership Scale for Sports (LSS) versions - coaches' perceptions of their own behavior and athletes' preferences and perceptions of their coaches' behavior. We used the original LSS developed by Chelladurai and Saleh (1980) and the recent 25-item version of the athletes' perceptions of their coaches' behavior version of the LSS by Chiu et al. (2016). To strengthen the psychometric development of the LSS, the present study also analyzes the measurement invariance of the coaches' self-perceptions and the athletes' preferences and perceptions of coaches' behavior scales across gender. Accordingly, we developed three studies. In Study 1, the five-factor structure of the original 40-item (Chelladurai \& Saleh, 1980) and the short 25-item (Chiu et al., 2016) LSS versions were examined using confirmatory factor analysis (CFA). In Study 2, we cross-validated the factor structure previously demonstrated with an independent sample. We also aimed at determining the degree to which the hypothesized model was invariant between genders. In Study 3, the criterion-related validity was tested by examining the associations between the factor structure of the LSS, defined in the previous studies, and athlete's satisfaction. All analyses were executed for each version of the actual coach behavior, perceived coach behavior, and preferred coach behavior. 


\section{Study 1}

Following the guidelines for testing short versions (Marsh et al., 2005), we utilized an archive sample of responses to the original 40-item LSS (Chelladurai \& Saleh, 1980) to examine the factorial validity of the 25-item versions of LSS (Chiu et al., 2016): actual coach behavior, perceived coach behavior, and preferred coach behavior.

\section{Method of Study 1}

\section{Participants and procedures}

The sample was composed by 373 athletes ( 224 females, 149 males; $M=22.67$ years old, $S D=7.45$, ranged from 10 to 46 years old) and their 115 coaches (62 females, 53 males; $M=37.41$ years old, $S D=8.82$, ranged from 23 to 55 years old) who had completed the original 40 -item version of the LSS. The sample belonged to an archive of data collected between 2005 and 2011. Participants were from the central coastal region of Portugal, and were involved in different levels of competition, including youth, junior, semi-professional, and professional team sports: soccer (54.4\%), volleyball (11\%), handball (28.2\%), and basketball (6.4\%). Participants had been involved with their team for about 2 years $(M=2.45$ years, $S D=1.10)$.

\section{Measures}

The Portuguese coach self-perceived, athlete perceived and athlete preferred leader behavior versions of LSS (Serpa, 1993; Serpa, Pataco, \& Santos, 1991) were used. All three versions include 40 items divided into five subscales. The Training-Instruction 
139 behavior subscale examines coaches' focus on training, skill instruction and sport

140 strategies. The Social Support subscale measures coaches' actions to create a supportive

141 team atmosphere. The Positive Feedback subscale examines coaches' abilities to provide

142 positive and encouraging performance feedback. Finally, the Democratic and Autocratic

143 subscales evaluate the degree to which coaches share sport-related decision-making with

144 their athletes or tend to maintain control of all decisions, respectively. Participants

145 respond on a 5-point Likert scale that range from 0 to 4 , i.e., (4) always (100\% of the

146 time); (3) often (75\%); (2) occasionally (50\%); (1) seldom (25\%), and (0) never (0\%).

\section{Statistical analysis}

148 A confirmatory factor analysis (CFA) was conducted with AMOS 20 (SPSS Inc,

149 Chicago IL) using maximum likelihood structural modelling procedure. The 150 appropriateness of the data of the overall models was evaluated through recommended fit 151 indexes (Hair, Black, Babin, Anderson, \& Tatham, 2014). Specifically, a good model fit 152 was assumed when the comparative-of-fit-index (CFI) and Tucker-Lewis index (TLI) 153 were larger than 90. A root mean square error of approximation (RMSEA) value lower 154 than .06 was indicative of good fit while an acceptable fit was assumed for values between 155.08 and .10 . Reliability was estimated through Cronbach's $\alpha$ coefficients $(>.70$ criterion; 156 Nunnally \& Bernstein, 1994). Because the Cronbach's $\alpha$ coefficient tends to 157 underestimate the scales reliability, composite reliability was also estimated (Raykov, 158 1997). Convergent validity was accepted when the average variance extracted (AVE) 
159 showed values greater than .50. Finally, discriminant validity was assumed when the

160 squared correlation between constructs were below AVE estimates for each construct 161 (Hair et al., 2014).

162

\section{Results of Study 1}

Preliminary analysis revealed $0.9 \%$ of missing data but no apparent pattern was observed. Data imputation was calculated using a maximization algorithm (Graham \& Hofer, 2000). As there are concerns about the cognitive ability of participants younger than 12 years of age to understanding the items (Scott, 2008), we tested potential mean differences in the 5-factors of athletes' perceptions and preferences versions of LSS between the age groups of 9 to $12(n=41)$ and 13 to $46(n=332)$ years old. No significant differences were found in all 5-factors of LSS between these age groups $(p>0.05)$.

Additionally, Mardia's coefficients were above the recommended threshold for multivariate normality (Byrne, 2010): 16.19, 18.40, and 62.10 for the coach selfperceived behavior, the athletes' perceived coach behavior, and the athletes' preferred coach behavior versions, respectively. Thus, the Bollen-Stine bootstrap (B-S) on 2000 samples was applied to the subsequent analysis.

\section{Construct validity}

The original 40-item LSS model demonstrated a poor fit to the data for all scales (Table 1): coach self-perceived behavior $($ e.g., $\mathrm{CFI}=.802$, RMSEA $=.112$ ), athlete 
perceived coach behavior (e.g., $\mathrm{CFI}=.854$, RMSEA $=.096$ ), and athlete preferred coach

179 behavior (e.g., CFI $=.862$, RMSEA $=.093$ ).

Following Chiu et al. (2016), we also tested the 25-item model and results revealed an adjustment to the data below the cutoff values: coach self-perceived behavior (e.g., $\mathrm{CFI}=.834, \mathrm{RMSEA}=.093$ ), athlete perceived coach behavior (e.g., $\mathrm{CFI}=.886, \mathrm{RMSEA}$ $=.091)$, and athlete preferred coach behavior $($ e.g., $\mathrm{CFI}=.891, \mathrm{RMSEA}=.082)($ Table 1). An analysis of the modification indexes revealed items with factor loadings below the recommended values (<.50; Hair et al., 2014) in all subscales. Moreover, reliability coefficients for the coach self-perceived and athlete perceived autocratic behavior and social support subscales were also below the recommended values $(<.70)$. The readjustment led to a 15 -item solution for the three versions with three items in each dimension.

The results obtained for the 15-item models indicated an acceptable fit to the data: coach self-perceived behavior (e.g., $\mathrm{CFI}=.913, \mathrm{RMSEA}=.072$ ), athlete perceived coach behavior (e.g., $\mathrm{CFI}=.967, \mathrm{RMSEA}=.046)$, and athlete preferred coach behavior (e.g., $\mathrm{CFI}=.968, \mathrm{RMSEA}=.042)$. In general, both CFI and TLI values met the good fit criteria while RMSEA was indicative of an acceptable fit (see Table 1).

For each 15-item LSS scales, all items showed moderate to high factor loadings: for the coaches' self-perceived version the factor loadings ranged from .63 (item 2 of 
Democratic Behavior) to .86 (item 2 of Positive Feedback); for the athletes' perceived coach behavior version, factor loadings ranged from .64 (item 1 of Autocratic behavior) to .91 (item 2 of Training and Instruction), and for the athletes' preferred coach behavior version, factor loadings ranged from .60 (item 3 of Autocratic Behavior) to .93 (item 1 of Positive Feedback), as indicated in the Table 2.

\section{Reliability, and convergent and discriminant validity of Study 1} subscales. Convergent validity was accepted for all subscales as AVE values ranged from .51 (athletes' perceived and preferred autocratic coach behaviors) to .83 (athletes' preferred positive feedback coach behaviors). Discriminant validity was assumed for AVE values greater than the squared correlation between constructs for each LSS short versions. The Cronbach $\alpha$ coefficients of .75 (athlete's perceived and preferred autocratic coach behaviors) and .93 (athlete's preferred positive feedback coach behaviors) support the constructs' reliability. Composite reliability values slightly above those of the corresponding Cronbach's $\alpha$ confirm the subscales reliability, with values ranging from

214.76 (athlete's perceived and preferred autocratic coach behaviors) to .94 (athlete's preferred positive feedback coach behaviors)

\section{Implications of Study 1}


The aim of Study 1 was to examine the factorial validity of the 25 -item versions

219 (Chiu et al., 2016): actual coach behavior, perceived coach behavior, and preferred coach behavior. For this purpose, an archive sample of responses to the original LSS versions was used to test validity and reliability of the short LSS 5-factor structure. Findings showed that the 25 -item version did not fit the data. Based on modification indices, an adjustment was made to the factorial structure, resulting in a 15-item version of LSS (see Appendix). This LSS-15 showed acceptable factorial structure, and the modified solution was consistent with MML (Chelladurai, 2007). Reliability and convergent and discriminant validity estimates provide additional support for the psychometric characteristics of the 15-item LSS. Overall, these results support the need for the structural refinement of the 25 -item version in the three versions of the LSS, resulting in a shorter 15-item version with stronger psychometric qualities.

\section{Study 2}

Following the initial development of the LSS-15, the purpose of study 2 was to test its factor structure measurement invariance across two independent samples and across gender.

\section{Method of Study 2}

\section{Participants and procedures}

The sample of Study 2 involved 817 athletes (297 females, 520 males; $M=17.58$ 
males; $M=28.69$ years old, $S D=8.58$, ranging from 19 to 64 years old). Participants in study 2 were from the north region of Portugal. They had been part of their current team for an average of 3.1 years $(S D=1.25)$ and represented a variety of competitive team sports: soccer (55\%), volleyball (12.1\%), handball (12.9\%), basketball (12.1\%), and rink hockey $(7.9 \%)$. Most teams practiced 3 or 4 times per week $(53 \%)$.

Following ethical approval from the university's ethical committee, research assistants trained in ethical principles regarding research involving human subjects, contacted several clubs and sport federations. Athletes completed the measures including perceived and preferred coach leadership behavior. Coaches completed the self-perceived version of coach behaviors. Participants completed the questionnaires at the beginning or at end of a training session. Considering concerns about the quality of responses to LSS by children under the age of 12 , we followed procedures used in other studies (e.g., Marcén, Gimeno, \& Gómez, 2016; Martin, Jackson, Richardson, \& Weiller, 1999) and read them each item out loud $(n=38)$. Data collection took place between 2015 and 2017.

Data collection quality control was assured by a randomized post contact to participants through e-mail by the first two authors.

\section{Measures}

The self-perceived coach behavior, athlete perceived, and preferred coach behavior 15-item versions tested in Study 1 were used in Study 2. All three short versions included 
258 Social Support, and Positive Feedback), each composed of three items. The response

259 categories ranged from 0 to 4 , i.e., (4) always (100\% of the time); (3) often (75\%); (2) occasionally (50\%); (1) seldom (25\%), and (0) never (0\%).

261

262

263

264

265

266

267

268

\section{Statistical analysis}

A multigroup CFA was performed to test the model invariance based on responses to the LSS-15 used in the Study 1 and Study 2 (Byrne, 2010). The chi-square $\left(\chi^{2}\right)$ test of significance and CFI difference $(\Delta \mathrm{CFI})$ values were used to examine the invariance between nested models (Cheung \& Rensvold, 2002). Invariance is assumed if $\chi^{2}$ for model comparison is not statistically significant; however, $\chi^{2}$ is influenced by sample size, thus changes in the $\triangle \mathrm{CFI}$ greater than .01 were also considered when testing the measurement invariance between groups (Cheung \& Rensvold, 2002). This test follows a sequential order of nested models, including the Model 1 - unconstrained, the Model 2 - constrained factor loading, and Model 3 - constrained factor variances-covariances. This statistical procedure was used for all three LSS-15 scales.

\section{Results of Study 2}

As in Study 1, due to concerns about the cognitive ability of children under 12 years old to understanding the items (Scott, 2008), possible differences between participants aged less or equal 12 years old $(n=38)$ and over 12 years old $(n=779)$ were tested. No statistically significant differences were found in all factors of the LSS-15 $(p>0.05)$.

\section{Cross-validation}


We tested whether the 15 -item version generalize to a cross-validation sample. In

279 the initial Model 1, the a priori factor structure was fitted separately for each version with no invariance constraints and it showed good fit indexes (see Table 1). The Model 2 factorial loadings was constrained to be equal across the two samples for the coaches' self-perceived behavior, athletes perceived coach behaviors, and preferred coach behaviors (i.e., $\Delta \mathrm{CFI} \leq .01)$ versions. In Model 3, the $\chi^{2}$ results $(p<.05)$ suggest that this model exceeds the invariance criterion for coaches' self-perceived behavior, $\chi^{2}(200)=$ 543.38, $p=.000$, athletes perceived coach behaviors, $\chi^{2}(200)=578.43, p=.001$, and preferred coach behaviors, $\chi^{2}(200)=472.35, p=.002$. However, in general models fit show no substantial decrease (e.g., RMSEA $\leq .07$ ), with the exception of the difference between Model 1 and Model 3 of the coaches' self-perceived behavior version, which was significantly worse (Table 1). The relatively small sample of coaches in Study 1 ( $n$ = 115) may potentiate inaccurate bootstrapped results (Yung \& Bentler, 1996). Nevertheless, the factor variance and covariance non-invariance suggest that the results from the coaches' version must be carefully analyzed in future studies. of the cross-validation sample. All of the LSS-15 items presented moderate to high factor loadings ranging from .55 (item 1 of autocratic behavior) to .91 (item 1 of democratic behavior). Also, composite reliability values of .73 (coaches' self-perception of 
evidence for the subscales reliability. Average variance extracted (AVE) values demonstrated convergent validity for all LSS-15 subscales (> .50; Hair et al., 2014), except for the autocratic behavior subscale of the coach's self-perception version which revealed a marginal value of .48 .

\section{[TABLE 4]}

\section{Gender invariance}

To analyze the gender invariance, the samples from Study 1 and Study 2 were combined to obtain a set of female and male athletes (521 and 669, respectively) and coaches (164 and 302, respectively). A multigroup CFA was performed to test gender invariance. The unconstrained model showed very good fit for both female and male groups for the coaches' self-perceived behavior, athletes perceived coach behaviors, and preferred coach behaviors versions. Also, the constrained Model 2 factor loadings was invariant across gender in all three LSS-15 scales (i.e., $\Delta$ CFI $\leq .01$ ); however, the constrained Model 3 factor variances-covariances revealed significant differences across gender in the coaches' self-perceived behavior and athletes preferred coach behaviors models (i.e., $\triangle \mathrm{CFI} \geq .01$ ). Table 1 shows the information pertaining to gender measurement invariance in all three LSS-15.

\section{Implications of the Study 2}

The aim of Study 2 was to test the measurement invariance of the 15 -item version of LSS across two independent samples (i.e., cross-validation) and across gender. This 
study provides a first to verify the LSS-15 measure invariance of the self-perceived coach

319 behavior, athlete perceived, and preferred coach behavior. Findings support the factor loadings invariance of all versions across two independent samples and across gender, which suggests that the factors are assessed similarly by participants in both groups. However, the constrained factor variances-covariances revealed differences across independent samples in the coaches' self-perceived behavior version, and across gender in the coaches' self-perceived behavior and athletes preferred coach behaviors versions. This means that one group tends to answer systematically with higher or lower values to certain items in comparison to the other group. In general, these psychometric findings show that athletes perceived version of LSS-15 operates equally across all groups, but precautions should be taken with eventual score bias in the responses of coaches' selfperceived and athletes preferred scales of the LSS-15.

\section{Study 3}

After the assessment of reliability, factorial, convergent and discriminant validities criterion validity of the LSS by examining its relationships with athletes' satisfaction.

334 Chelladurai $(1993 ; 2007)$ developed the congruence hypothesis by stating that athletes' satisfaction with their sport experience is stronger when the athletes' perceptions of their coach behaviors match athletes' preferences for their coach's behavior. The congruence hypotheses has been supported significant associations between athletes' satisfaction and 
their preferences and perceptions of leader behaviors (e.g., Andrew, 2009; Riemer \& Chelladurai, 1995). As such, a structural equation model was used to test the extent to which preferences and perceptions of the leader's behaviors are associated with athletes' satisfaction.

342

\section{Participants and procedures}

Participants were 246 male soccer players with ages ranging from 18 to 35 years $\left(M_{\text {age }}=22.68, S D=3.58\right)$. The respondents competed in regional leagues of the north region of Portugal. Participants reported 7 to 19 years of experience playing soccer $(M=$ $13.06, S D=3.94)$, and partaking in 4 to 5 training sessions per week.

Team managers from 14 soccer clubs were contacted to obtain permission to meet with their athletes. Athletes were then informed about the purpose of study as well as their rights for voluntary participation and confidentiality. Athletes completed the questionnaires at the beginning or at the end of a training session. The data collection was conducted during 2017 and 2018. Procedures of this Study 3 were identical to those used in Study 2.

\section{Measures}

LSS-Short Version. The athletes' perceived and preferred coach behavior of the LSS-15 developed in Studies1 and 2 were used in Study 3.

Athlete Satisfaction Questionnaire. The Portuguese version of the Athlete Satisfaction Questionnaire (ASQp; Borrego, Leitão, Alves, Silva, \& Palmi, 2010; Riemer 
\& Chelladurai, 1998) was used in Study 3. The ASQp is a 54-item questionnaire that contains 14 dimensions of athlete satisfaction. Participants indicated the degree of satisfaction with aspects of their sport experience. Answers were provided on seven-point Likert scales ranging from "not at all satisfied" (1) to "extremely satisfied" (7). To limit the length of the questionnaire, we selected four subscales (14 items) of the ASQp: training and instruction satisfaction (three items; e.g., "I am satisfied with the training I receive from the coach during the season"); personal treatment satisfaction (five items; e.g., "I am satisfied with the recognition I receive from my coach"); team performance satisfaction (three items; e.g., "I am satisfied with the team's win/loss record this season"), and individual performance satisfaction (three items; e.g., "I am satisfied with the degree of which I have reached my performance goals during the season"). According to Riemer and Chelladurai (1998), the first two subscales measure athletes' satisfaction with coaching behaviors related to training quality, and individual and team development, while the latter two subscales measure athletes' satisfaction with individual and team outcomes. These 14 items have been used in previous studies (e.g., Riemer \& Toon, 2001).

\section{Statistical analysis}

To further assess the validity of the LSS-15, a structural model was performed to examine the relationships between athletes' preference and perceived coach behaviors with athletes' performance satisfaction. 


\section{Results of Study 3}

Preliminary analysis revealed $0.5 \%$ of missing data without an observed fixed pattern. Thus, missing values were replaced using the maximum likelihood algorithm (Graham \& Hofer, 2000). Skewness values ranged from -1.68 to 2.81, while kurtosis values ranged from -1.48 to 4.45 . Additionally, the Mardia's coefficient (72.06) for multivariate kurtosis exceeded the value considered adequate for data normality. Hence, a Bollen-Stine bootstrapping was performed in subsequent analysis (Byrne, 2010). Table 4 shows descriptive statistics and correlations between all variables. Considering the descriptive statistics, the training-instruction behaviors was the dimension with the highest scores in the athletes' preferred $(M=4.81, S D=.72)$ and perceived $(M=4.18, S D=.59)$ versions. The Cronbach $\alpha$ coefficients ranged from .68 (autocratic behavior preference) to .89 (personal treatment satisfaction). Composite reliability values support all subscales reliability. Average variance extracted (AVE) values were equal to or greater than .50 , revealing convergent validity. Discriminant validity was evidenced in all measures for the square of the correlations between the constructs was below the AVE values (Hair et al., 2014).

The goodness-of-fit indices computed to assess the measurement model $\left[\chi^{2}(811)=\right.$ 396 $1075.06, p<.001, \mathrm{CFI}=.931, \mathrm{TLI}=.924, \mathrm{RMSEA}=.041(90 \% \mathrm{CI}=.038, .049), \mathrm{SRMR}$ $397=.043]$ and the structural model $\left[\chi^{2}(861)=1239.51, p<.001\right.$, CFI $=.919$, TLI $=.912$, 
$\mathrm{RMSEA}=.055(90 \% \mathrm{CI}=.059, .069), \mathrm{SRMR}=.054]$ indicated an acceptable fit to the data.

Figure 1 shows the relationships between preferences and perceptions of leader

401

402

403

404

405

406

407

408

409

410

411

412

413

414

415

416

417 behaviors with athletes' satisfaction. The perception of training-instruction behaviors was associated with satisfaction with individual performance $(\beta=.19 ; \mathrm{CI}=.10, .38)$, and quality of training and instruction $(\beta=.18 ; \mathrm{CI}=.13 .36)$. Perception of positive feedback behaviors was related with satisfaction with individual performance $(\beta=.36$; $\mathrm{CI}=.16$, $.49)$ and team performance $(\beta=.45 ; \mathrm{CI}=.21, .59)$.

Also, preference and perception of the coach's democratic behavior were associated $(\beta=.39 ; \mathrm{CI}=.28, .56)$; in turn, the perception of the coach's democratic behavior is associated with satisfaction with personal treatment $(\beta=.42 ; \mathrm{CI}=.28, .51)$. The results also showed an association between preference and perception of autocratic behavior $(\beta$ $=.41 ; \mathrm{CI}=.22, .46)$ which, in turn, is negatively associated to satisfaction with individual performance $(\beta=-.19 ; \mathrm{CI}=-.26,-.09)$, team performance $(\beta=-.16 ; \mathrm{CI}=-.22,-.03)$ and personal treatment $(\beta=-.14 ; \mathrm{CI}=-24,-.01)$. Moreover, preference and perception of social support are associated $(\beta=.48 ; \mathrm{CI}=.29, .61)$, which, in turn, is associated with satisfaction with the team performance $(\beta=.47 ; \mathrm{CI}=.38, .57)$ and with personal treatment $(\beta=.41 ; \mathrm{CI}=.26, .53)$.

[FIGURE 1] 


\section{Common method bias considerations}

The complexity of the relationships between variables integrated in the model may lead to common method bias (CMB), that is, the relationships between variables may be determined by the measurement method instead of the actual participants' response intentions (Podsakoff, MacKenzie, Lee, \& Podsakoff, 2003). To access the possibility of $\mathrm{CMB}$, the common latent factor test was performed to examine potential false relationships between variables. The difference between the standardized estimates with and without the common latent factor ranged between 0.074 and 0.001 , which leads to the rejection of the possibility of CMB (Williams, Côté, \& Buckley, 1989).

\section{Implications of the Study 3}

The purpose of the Study 3 was to determine whether perceived and preferred LSS15 scales were associated with athletes' satisfaction. Findings indicate that the relationships between preference and perception of three of the coach behaviors, i.e., democratic behavior, autocratic behavior and social support, play an important role in determining athletes' satisfaction. A longstanding history of studies associates these coach behaviors with athletes' satisfaction (Chelladurai, 2007). However, these results challenged this notion, particularly with the assessment of a model including preferences and perceptions of coach's behaviors, and athlete's satisfaction variables, as well as the individual significance of the parameters in a single methodological framework.

\section{Discussion}


In this investigation, we followed the initial attempt of Chiu et al. (2016) to demonstrate the appropriateness of a short version of the widely used LSS, developed over 30 years by Chelladurai and colleagues (Chelladurai \& Riemer, 1998; Chelladurai \& Saleh, 1980). A 15-item short form of the three Leadership Scale for Sports versions, coaches' perceptions of their own behavior, athletes' perceptions of their coaches' behavior, and athletes' preferences for their coaches' behavior, were validated and its psychometric characteristics were examined in three independent studies.

The extensive empirical literature on the Multidimensional Model of Leadership (MML) demonstrates that the LSS is a widely used instrument for the study of sport leadership. Theoretical models should guide psychometric development (Marsh et al., 2005). As such, the theoretical structure of MML was entirely reflected in the LSS-15 and supported by factorial validation and measurement invariance. Thus, the development, evaluation and refinement of the short measure was systematically informed by theory and past empirical research. In this study, the LSS-15 also provided an important basis to evaluate and confirm the theory on which the original LSS was grounded.

Findings of studies 1 and 2 supported the construct validity of the LSS-15. First, using CFA, we found that the fit of the proposed multidimensional leadership structure of five factors was adequate for the three versions. The results of model fit indexes of the LSS-15 are consistent with previous studies where the LSS original structure was used 
(e.g., Chelladurai \& Riemer, 1998; Fletcher \& Roberts, 2013). Second, convergent and 459 discriminant validities of the new short form were explored using the average variance extracted estimates (Hair et al., 2014). This means that although the five factors of the three versions of the LSS are related, they represent theoretically distinct constructs. The scores representing all combinations of the three LSS-15 versions had robust psychometric properties.

In general, findings suggest that the LSS-15 performed better in comparison to the 25-item version of Chiu et al. (2016). It is important to note that Chiu et al (2016) shortened the original scale to 25 items through consultation with a panel of experts. However, the recommendations suggest that the basis for choosing the items must be the psychometric qualities based on the long form (e.g., Marsh et al., 2005; Smith, McCarthy, \& Anderson, 2000).

Also, as recommended by Marsh et al. (2005), multiple-group invariance tests between the sample of the Study 1 and the sample of the Study 2 demonstrated that the factor loadings of the 15-item versions were invariant; however, the chi-square and CFI differences in the factor variance covariance suggest measurement non-invariance.

474 Specifically, results revealed differences in factor variances between the two samples and across gender for the 15-item short version of coaches' self-perceived behavior. These differences should be interpreted in light of sensitivity of the chi-square difference to 
item version of coaches' self-perceived behaviors that intend to analyze group differences

479 should consider larger sample sizes.

The reliability coefficients of the LSS-15 showed moderate consistency estimates

481

482

483

484

485

486

487

488

489

490

491

492

493

494

495

496

497 for all subscales. Values below .70 (Nunnally \& Bernstein, 1994) were found in the 25-

item LSS version in the autocratic behavior and social support subscales showing that some items seem to interfere with the subscale reliability. Moderate internal consistency values were obtained for the autocratic behavior subscales in the 15-item LSS when compared to the 25 -item version. This result is relevant because the autocratic behavior subscales have been afflicted with reliability problems in several studies (see reviews by Chelladurai 1993, 2007).

As defined by the MML (Chelladurai, 2007), the greater the congruence between preference and perception of current leader behaviors, the greater the satisfaction of athletes. Thus, considering the findings from Study 3, when the coach provides the desired level of democratic behaviors, they tend to influence athletes' satisfaction with their personal treatment, i.e., the athlete's perception of their coach's recognition and the quality of the coach-athlete interpersonal relationship. Also, the association between preferred and perceived social support behaviors tends to determine athletes' satisfaction with team performance and their relationship with their coach (Andrew, 2009).

In Study 3, it was also found that autocratic behaviors can negatively influence athletes' satisfaction with individual and team performance, and the quality of the 
interpersonal relationship with the coach. These results seem to support current knowledge in the area of leadership in sport. For example, using hierarchical regression analysis, Andrew (2009) found that congruence between low levels of preferred and perceived autocratic behaviors significantly increased all variables of athlete satisfaction (i.e., training and instruction, team performance, individual performance, and personal treatment). Nevertheless, due to a sound methodological approach based on SEM, the results of Study 3 strengthen the conclusions of previous studies that used hierarchical regressions to analyze the relationships between preferences and perceptions of coach behaviors with athletes' satisfaction. Indeed, SEM tests the global adjustment of the theoretical model as well as the significance of the relationships between all variables in a single framework.

\section{Practical implications of the 15-item LSS}

510 The 15-item LSS can be applied to the study of coach behavior and used in interventions with a large spectrum of athletic populations, such as children, adolescent and adult athletes of both genders. Also, this short version can be a useful tool to give quick feedback to coaches who are undergoing behavior assessment and professional

514 development action plans. Moreover, the findings regarding the associations between leadership and athletes' satisfaction inform coaches about their efficacy in the use of management strategies to improve athletes' satisfaction with the quality of training and

517 personal relationships. Finally, because the present study supports the validation of short 
518 versions of a self-perceived coach behavior scale, and athletes' perceived and preferred

519 coach behavior scales, congruence between these concepts can be empirically examined.

520 Such examination will allow the development of research that may inform specific

521 training schedules in coaching leadership.

\section{Limitations and future research}

523 This investigation has several limitations. First, the main concern of this study was

524 that to examine the psychometric proprieties of the LSS-15 using an independent 525 administration of both short and long versions to the same sample, as recommended by 526 Smith et al. (2000). However, Marsh et al. (2005) argued that this standard guideline "is 527 typically impractical and, perhaps, unnecessary" (p. 98), due to the long instrument 528 administration procedures required. Specifically, for this investigation, considering the 529 three versions of both short and full forms, the administration of the instrument would 530 comprise about 165 items. To overcome this rigorous guideline, as suggested by Marsh 531 et al. (2005), we conducted a CFA multiple-group invariance analysis with two 532 independent samples. Second, given the relatively small sample size of coaches, 533 conclusions from measurement invariance should be taken with caution. Third, future 534 research should explore measurement invariance issues across other sub-groups (e.g., age, sports). Finally, the three studies were developed with three independent Portuguese samples; however, cross-cultural studies are relevant to evaluate whether the LSS-15 
537 works equally well across different nationalities and ethnic groups (see reviews by 538 Chelladurai, 2007; Riemer, 2007).

539 In summary, this investigation provides evidence for the factorial validity, 540 reliability and measurement variance of the three versions of the LSS-15 to evaluate and

541 describe leadership behaviors in sport. As noted, this new short version is a valid and 542 reliable alternative to the 25-item LSS (Chiu et al., 2016) and long 40-item LSS

543 (Chelladurai \& Saleh, 1980), which is particularly beneficial when researchers need to

544 use a brief measure of leadership in applied settings or when study designs include 545 evaluation of multiple variables with the same sample. 


\section{References}

547 Andrew, D. P. S. (2009). The impact of leadership behavior on satisfaction of college tennis players: A test of the leadership behaviour congruency hypothesis of the Multidimensional Model of Leadership. Journal of Sport Behavior, 32, 261-277.

Byrne, B.M. (2010). Structural equation modelling with AMOS: Basic concepts, applications, and programming (2nd ed.). New York: Routledge.

Chiu, W., Rodriguez, F. M., \& Won, D. (2016). Revisiting the Leadership Scale for Sports: Examining factor structure through exploratory structural equation modelling. Psychological Reports, 119, 435-449.

Chelladurai, P. (1993). Leadership. In R. Singer, \& L. Tennant (Eds.), Handbook of research on sport psychology (pp. 647-671). New York: Macmillan.

Chelladurai, P. (2007). Leadership in sports. In G. Tenenbaum \& R.C. Eklund (Eds.), Handbook of sport psychology (3rd ed., pp. 113-135). New Jersey: John Wiley \& Sons.

Chelladurai, P., \& Carron, A.V. (1983). Athletic maturity and preferred leadership. Journal of Sport Psychology, 5, 371-380.

562 Chelladurai, P., \& Riemer, H.A. (1998). Measurement of leadership in sport. In J.L. Duda (Ed.), Advances in sport and exercise psychology measurement (pp. 227-256). Morgantown, WV: Fitness Information Technology. 
565 Chelladurai, P., \& Saleh, S.D. (1980). Dimensions of leader behavior in sports: Development of a leadership scale. Journal of Sport Psychology, 2, 34-45.

567

568

569

570

571

572

573

574

575

576

577

578

579

580

581

582

583

584

Cheung, G. W., \& Rensvold, R. B. (2002). Evaluating goodness-of-fit indexes for testing measurement invariance. Structural Equation Modeling, 9, 233-255.

Fletcher, R.B., \& Roberts, M.H. (2013). Longitudinal stability of the Leadership Scale for Sports. Measurement in Physical Education and Exercise Science, 17, 89-104.

Graham, J. W., \& Hofer, S. M. (2000). Multiple imputation in multivariate research. In T. D. Little, K. U. Schnable, \& J. Baumert (Eds.), Modeling longitudinal and multilevel data: Practical issues, applied approaches, and specific examples (pp. 201-218). Mahwah, NJ: Erlbaum.

Hair, J.F., Jr., Black, W.C., Babin, B.J., \& Anderson, R.E. (2014). Multivariate data analysis: A global perspective (7th ed.). Upper Saddle River, NJ: Pearson.

Kline, R.B. (2011). Principles and practice of structural equation modeling (3rd ed.). New York: Guilford press.

Kwon, H. H., Koh, K. T., Pyun, D. Y., \& Wang, J. (2009). Psychometric properties of leadership scale for sport: The case of Singaporean secondary school athletes. International Journal of Sport Management, 10, 367-381.

Kwon, H. H., Pyun, D. Y., Han, S., \& Ogasawara, E. (2011). Testing for factorial invariance of the modified leadership scale for sports: Using a Japanese version. Asia Pacific Journal of Education, 31, 65-76. 
Márcen, C., Gimeno, F., \& Gómez, C. (2016). Adapting Leadership Scale for Sport (LSS) in a high-performance center coaches and athletes. Cuadernos de Psicología del Deporte, 16, 21-32.

Martin, S. B., Richardson, P. A., \& Weiller, K. H. (1999). Coaching preferences of adolescent youths and their parents. Journal of Applied Sport Psychology, 11, 247262.

Marsh, H. W., Ellis, L.A., Parada, R.H., Richards, G., \& Heubeck, B.G. (2005). A short version of the self-description questionnaire II: Operationalizing criteria for shortform evaluation with new applications of confirmatory factor analyses. Psychological Assessment, 17, 81-102.

Nunnally, J.C., \& Bernstein, I.J. (1994). Psychometric theory (3rd ed.). New York: McGraw-Hill.

Podsakoff, P., MacKenzie, S., Lee, J., \& Podsakoff, N. (2003). Common method biases in behavioral research: A critical review of the literature and recommended remedies. Journal of Applied Psychology, 88, 879-903.

Raykov, T. (1997). Estimation of composite reliability for congeneric measures. Applied Psychological Measurement, 21, 173-184.

Riemer, H.A. (2007). Multidimensional model of coach leadership. In S. Jowett \& D. Lavallee (Eds.), Social psychology in sport (pp. 57-74). Champaign, IL: Human Kinetics. 
Riemer, H.A., \& Chelladurai, P. (1995). Leadership and satisfaction in sport. Journal of Sport and Exercise Psychology, 17, 276-293.

Scott, J. (2008). Children as respondents: The challenge for quantitative methods. In P. Christensen \& A. James (Eds), Research with children: Perspectives and practices (2nd ed.) (pp. 87-108). New York, NY: Routledge.

Serpa, S. (1993). Avaliação dos processos de interacção treinador-atleta e liderança no desporto [Evaluation of the processes of coach-athlete interaction and leadership in sport]. Ludens, 13, 9-16.

Serpa, S., Pataco, V., \& Santos, F. (1991). Leadership patterns in handball international competition. International Journal of Sport Psychology, 22, 78-89.

Smith, G. T., McCarthy, D. M., \& Anderson, K. G. (2000). On the sins of short-form development. Psychological Assessment, 12, 102-111.

Yung, Y-F., \& Bentler, P. M. (1996). Bootstrapping techniques in analysis of mean and covariance structures. In G. A. Marcoulides \& R. E. Schumacker (Eds.), Advanced structural equation modeling: Issues and techniques (pp. 195-226). Mahwah, NJ: Erlbaum.

Williams. L. J., Cote, J.A., \& Buckley, M.R. (1989). Lack of method variance in selfreported affect and perceptions of work: Reality or artifact? Journal of Applied Psychology, 74, 462-468. 


\section{Appendix}

Summary description of Chelladurai \& Saleh's (1980) 40-item LSS for each subscale

Stem: I, as a coach... (coach version) or My coach... (athletes preferred and perceived versions)

\section{Training and Instruction}

Sees to it that every athlete is working to his/her capacity (1) *

Explain to each athlete the techniques and tactics of sport $(5)^{* \dagger}$

Pay special attention to correcting athlete's mistakes $(8){ }^{* \dagger}$

Make sure that his part in the team is understood by all the athletes (11)

Instruct every athlete individually in the skills of the sport (14)

Figure ahead on what should be done (17)

Explain to every athlete what he should and what he should not do (20)

Expect every athlete to carry out his assignment to the last detail (23)

Point out each athlete's strengths and weaknesses (26)

Give specific instructions to each athlete as to what he should do in every situation (29)

$* \dagger$

Sees to it that efforts are coordinated (32) *

Explain how each athlete's contribution fits into the total picture (35)

Specifies in detail what is expected to each athlete (38) *

\section{Democratic Behavior}

Ask for the opinion of the athletes on strategies for specific competitions (2) ${ }^{* \dagger}$

Get group approval on important matters before going ahead (9)

Let his/her athletes share decision making $(15)^{*} \dagger$

Encourages athletes to make suggestions on conducting practices (18) *

Let the group set its own goals (21)

Lets the athletes try their own way, even if they make mistakes (24) * 
Ask for the opinion of the athletes on important coaching matters (30) *

Let athletes work at their own speed (33)

Let the athletes decide on the plays to be used in a game (39)

Autocratic Behavior

Works relatively independent of the athletes (6) *

Does not explain his/her action (12) ${ }^{* \dagger}$

Refuse to compromise on a point $(27)^{* \dagger}$

Keeps to himself/herself (34) *

Speaks in a manner not to be questioned (40) $* \dagger$

Social Support

Helps the athletes with their personal problems (3) *

Helps members of the group settle their conflicts (7) ${ }^{*}$

Looks out for the personal welfare of the athletes (13)*

Do personal favors to the athletes (19)

Express affection he feels for his/her athletes $(22)^{\dagger}$

Encourage athletes to confide in him/her (25) *

Encourage close and informal relations with athletes (31) ${ }^{* \dagger}$

Invite athletes to his/her home (36)

Positive Feedback

Compliments an athlete for his performance in front of others (4) *

Tell an athlete when he/she does a particularly good job (10) ${ }^{* \dagger}$

Sees that an athlete is rewarded for a good performance (16) *

Express appreciation when an athlete performs well $(28) * \dagger$

Give credit when credit is due $(37)^{* \dagger}$

Note. ${ }^{*}$ Items included in Chiu et al. (2016) 25-item LSS version of athletes perceptions of coach behaviors; ${ }^{\dagger}$ Items included in the 15 -item for the three LSS version: coaches' perceptions of their own behavior, athletes' preferences and perceptions of their 
coaches' behavior; The numbers in parentheses at the end of each item refer to the number of items of the original 40-item LSS for review. 
Table 1

Summary of goodness of fit statistics for original LSS and LSS short versions models across two samples and gender.

\begin{tabular}{|c|c|c|c|c|c|c|c|}
\hline Models & $\chi^{2}$ & $d f$ & $p$ & CFI & $\Delta \mathrm{CFI}$ & TLI & RMSEA $\left(\mathrm{CI}_{90 \%}\right)$ \\
\hline \multicolumn{8}{|l|}{ Coaches self-perceived behavior } \\
\hline Study 1 sample $(n=115)-40$-item & 1489.56 & 730 & .000 & .802 & - & .799 & $.112(.102, .109)$ \\
\hline Study 1 sample $(n=115)-25$-item & 513.67 & 265 & .000 & .834 & - & .821 & $.093(.089, .097)$ \\
\hline Study 1 sample $(n=115)-15$-item & 104.91 & 80 & .032 & .966 & - & .955 & $.051(.016, .076)$ \\
\hline Study 2 sample $(n=351)-15$-item & 166.53 & 80 & .000 & .942 & - & .924 & $.069(.054, .083)$ \\
\hline M1 - Unconstrained & 271.50 & 160 & .000 & .950 & - & .934 & $.045(.035, .054)$ \\
\hline M2 - Factor loadings & 283.61 & 170 & .277 & .949 & $\leq .01$ & .937 & $.044(.035, .053)$ \\
\hline M3 - Factor variances-covariance & 543.38 & 200 & .000 & .846 & $\geq .01$ & .838 & $.070(.063, .077)$ \\
\hline \multicolumn{8}{|l|}{ Gender invariance } \\
\hline Female 15 -item model & 308.22 & 80 & .000 & .934 & - & .930 & $.056(.051, .058)$ \\
\hline Male 15-item model & 266.54 & 80 & .000 & .955 & - & .951 & $.033(.030, .036)$ \\
\hline M1 - Unconstrained & 316.86 & 160 & .000 & .932 & - & .926 & $.065(.059, .068)$ \\
\hline M2 - Factor loadings & 348.12 & 170 & .082 & .925 & $\leq .01$ & .920 & $.069(.063, .071)$ \\
\hline M3 - Factor variances-covariance & 665.79 & 200 & .000 & .840 & & .826 & $.081(.078, .085)$ \\
\hline \multicolumn{8}{|l|}{ Athletes perceived coach behavior } \\
\hline Study 1 sample $(n=373)-40$-item & 1108.37 & 730 & .000 & .854 & - & .844 & $.096(.093, .101)$ \\
\hline Study 1 sample $(n=373)-25$-item & 378.66 & 265 & .000 & .886 & - & .880 & $.091(.090, .097)$ \\
\hline Study 1 sample $(n=373)-15$-item & 308.67 & 80 & .000 & .923 & - & .898 & $.088(.078, .089)$ \\
\hline Study 2 sample $(n=817)-15$-item & 140.14 & 80 & .000 & .986 & _ & .982 & $.041(.029, .052)$ \\
\hline M1 - Unconstrained & 448.86 & 160 & .000 & .960 & - & .948 & $.047(.042, .052)$ \\
\hline M2 - Factor loadings & 460.24 & 170 & .329 & .960 & $\leq .01$ & .951 & $.046(.041, .051)$ \\
\hline M3 - Factor variances-covariance & 578.43 & 200 & .001 & .948 & $\geq .01$ & .951 & $.048(.044, .053)$ \\
\hline \multicolumn{8}{|l|}{ Gender invariance } \\
\hline Female 15 -item model & 183.06 & 80 & .000 & .979 & - & .970 & $.042(.032, .044)$ \\
\hline Male 15-item model & 166.12 & 80 & .000 & .981 & - & .973 & $.038(.033, .040)$ \\
\hline M1 - Unconstrained & 208.55 & 160 & .000 & .966 & - & .959 & $.047(.041, .051)$ \\
\hline M2 - Factor loadings & 216.43 & 170 & .282 & .965 & $\leq .01$ & .955 & $.043(.039, .048)$ \\
\hline M3 - Factor variances-covariance & 613.64 & 200 & .000 & .943 & $\geq .01$ & .935 & $.051(.046, .058)$ \\
\hline \multicolumn{8}{|l|}{ Athletes preferred coach behavior } \\
\hline Study 1 sample $(n=373)-40$-item & 977.84 & 730 & .000 & .862 & - & .093 & $.096(.092, .098)$ \\
\hline Study 1 sample $(n=373)-25$-item & 288.32 & 265 & .000 & .891 & - & .888 & $.082(.074, .089)$ \\
\hline Study 1 sample $(n=373)-15$-item & 196.08 & 80 & .000 & .968 & - & .958 & $.063(.052, .074)$ \\
\hline Study 2 sample $(n=817)-15$-item & 192.53 & 80 & .000 & .977 & - & .969 & $.056(.046, .066)$ \\
\hline M1 - Unconstrained & 388.62 & 160 & .000 & .973 & - & .965 & $.042(.037, .047)$ \\
\hline M2 - Factor loadings & 402.11 & 170 & .198 & .973 & $\leq .01$ & .966 & $.041(.036, .046)$ \\
\hline M3 - Factor variances-covariance & 472.35 & 200 & .002 & .968 & $\leq .01$ & .966 & $.041(.036, .046)$ \\
\hline \multicolumn{8}{|l|}{ Gender invariance } \\
\hline Female 15 -item model & 242.89 & 80 & .000 & .953 & - & .946 & $.049(.044, .056)$ \\
\hline Male 15-item model & 225.72 & 80 & .000 & .958 & - & .949 & $.042(.038, .047)$ \\
\hline M1 - Unconstrained & 332.45 & 160 & .000 & .944 & - & .931 & $.052(.046, .059)$ \\
\hline M2 - Factor loadings & 398.06 & 170 & .000 & .938 & $\leq .01$ & .922 & $.067(.061, .074)$ \\
\hline M3 - Factor variances-covariance & 653.87 & 200 & .451 & .911 & $\geq .01$ & .908 & $.071(.066, .078)$ \\
\hline
\end{tabular}


Table 2

Factor loadings and items descriptive statistics for each 15-item LSS short version.

\begin{tabular}{|c|c|c|c|c|c|c|c|c|c|c|c|c|c|c|c|}
\hline \multirow[t]{2}{*}{ Subscales/Items } & \multicolumn{5}{|c|}{$\begin{array}{l}\text { Coaches self-perceived behavior } \\
\qquad(n=115)\end{array}$} & \multicolumn{5}{|c|}{$\begin{array}{l}\text { Athletes perceived coach behavior } \\
\qquad(n=373)\end{array}$} & \multicolumn{5}{|c|}{$\begin{array}{l}\text { Athletes preferred coach behavior } \\
\qquad(n=373)\end{array}$} \\
\hline & Loadings & $\mathrm{M}$ & $\mathrm{SD}$ & $\mathrm{Sk}$ & $\mathrm{Ku}$ & Loadings & $\mathrm{M}$ & $\mathrm{SD}$ & $\mathrm{Sk}$ & $\mathrm{Ku}$ & Loadings & $\mathrm{M}$ & SD & $\mathrm{Sk}$ & $\mathrm{Ku}$ \\
\hline \multicolumn{16}{|l|}{ Training and Instruction } \\
\hline TI1 & 0.77 & 3.14 & 0.87 & -0.79 & -0.08 & 0.90 & 2.83 & 1.31 & -0.91 & -0.40 & 0.83 & 2.87 & 1.37 & -0.91 & -0.45 \\
\hline TI2 & 0.82 & 3.26 & 0.80 & -0.96 & 0.47 & 0.91 & 2.86 & 1.28 & -0.95 & -0.24 & 0.90 & 2.97 & 1.32 & -1.04 & -0.21 \\
\hline TI3 & 0.70 & 2.97 & 0.79 & -0.53 & 0.01 & 0.79 & 2.79 & 1.24 & -0.79 & -0.45 & 0.89 & 2.98 & 1.27 & -1.02 & -0.17 \\
\hline \multicolumn{16}{|l|}{ Democratic Behavior } \\
\hline DB1 & 0.78 & 2.16 & 0.84 & -0.33 & 0.08 & 0.78 & 2.53 & 1.08 & -0.46 & -0.41 & 0.74 & 2.73 & 1.24 & -0.61 & -0.75 \\
\hline DB2 & 0.63 & 2.28 & 0.82 & -0.41 & 0.27 & 0.72 & 2.47 & 1.15 & -0.42 & -0.55 & 0.66 & 2.64 & 1.20 & -0.55 & -0.57 \\
\hline DB3 & 0.79 & 2.12 & 0.88 & -0.11 & 0.14 & 0.73 & 2.53 & 1.12 & -0.42 & -0.56 & 0.82 & 2.74 & 1.18 & -0.61 & -0.55 \\
\hline \multicolumn{16}{|l|}{ Autocratic Behavior } \\
\hline $\mathrm{AB} 1$ & 0.73 & 1.77 & 1.07 & 0.35 & -0.38 & 0.64 & 1.91 & 1.35 & 0.14 & -1.18 & 0.78 & 1.93 & 1.52 & 0.06 & -1.45 \\
\hline $\mathrm{AB} 2$ & 0.79 & 1.47 & 1.19 & 0.64 & -0.36 & 0.79 & 1.83 & 1.38 & 0.17 & -1.23 & 0.76 & 1.95 & 1.52 & 0.06 & -1.48 \\
\hline AB3 & 0.69 & 1.30 & 1.13 & 0.55 & -0.49 & 0.73 & 1.73 & 1.50 & 0.25 & -1.40 & 0.60 & 1.69 & 1.61 & 0.35 & -1.36 \\
\hline \multicolumn{16}{|l|}{ Social Support } \\
\hline SS1 & 0.66 & 2.74 & 1.01 & -0.54 & -0.18 & 0.81 & 2.64 & 1.23 & -0.54 & -0.72 & 0.79 & 2.85 & 1.26 & -0.79 & -0.54 \\
\hline $\mathrm{SS} 2$ & 0.71 & 2.54 & 0.93 & -0.43 & -0.17 & 0.69 & 2.56 & 1.18 & -0.46 & -0.71 & 0.75 & 2.59 & 1.26 & -0.47 & -0.86 \\
\hline SS3 & 0.82 & 2.74 & 0.95 & -0.40 & -0.48 & 0.77 & 2.71 & 1.19 & -0.60 & -0.60 & 0.90 & 2.78 & 1.27 & -0.70 & -0.67 \\
\hline \multicolumn{16}{|l|}{ Positive Feedback } \\
\hline PF1 & 0.78 & 3.20 & 0.89 & -1.20 & 1.36 & 0.89 & 2.88 & 1.24 & -0.95 & -0.18 & 0.93 & 2.95 & 1.33 & -1.02 & -0.30 \\
\hline PF2 & 0.86 & 3.25 & 0.97 & -1.49 & 1.89 & 0.89 & 2.95 & 1.28 & -1.05 & -0.10 & 0.91 & 2.96 & 1.36 & -1.05 & -0.27 \\
\hline PF3 & 0.80 & 3.27 & 0.95 & -1.55 & 1.28 & 0.83 & 2.91 & 1.25 & -1.01 & -0.05 & 0.90 & 2.92 & 1.40 & -0.96 & -0.52 \\
\hline
\end{tabular}

Note $. \mathrm{M}=$ Mean; $\mathrm{SD}=$ Standard deviation; $\mathrm{Sk}=$ Skewness; $\mathrm{Ku}=$ Kurtosis 
Table 3

Means, standard deviations, reliabilities, average variance extracted (AVE) and squared correlations among subscales.

\begin{tabular}{|c|c|c|c|c|c|c|c|c|c|c|c|c|c|c|c|}
\hline \multirow{2}{*}{ Subscales } & \multicolumn{15}{|c|}{ Correlation matrix } \\
\hline & $\mathrm{TI}^{\mathrm{a}}$ & $\mathrm{TI}^{\mathrm{b}}$ & $\mathrm{TI}^{\mathrm{c}}$ & $\mathrm{DB}^{\mathrm{a}}$ & $\mathrm{DB}^{\mathrm{b}}$ & $\mathrm{DB}^{\mathrm{c}}$ & $\mathrm{AB}^{\mathrm{a}}$ & $\mathrm{AB}^{\mathrm{b}}$ & $\mathrm{AB}^{\mathrm{c}}$ & $\mathrm{SS}^{\mathrm{a}}$ & $\mathrm{SS}^{\mathrm{b}}$ & $\mathrm{SS}^{\mathrm{c}}$ & $\mathrm{PF}^{\mathrm{a}}$ & $\mathrm{PF}^{\mathrm{b}}$ & $\mathrm{PF}^{\mathrm{c}}$ \\
\hline $\mathrm{TI}^{\mathrm{a}}$ & 1.00 & & & & & & & & & & & & & & \\
\hline $\mathrm{TI}^{\mathrm{b}}$ & .03 & 1.00 & & & & & & & & & & & & & \\
\hline $\mathrm{TI}^{\mathrm{c}}$ & .07 & $.74 * *$ & 1.00 & & & & & & & & & & & & \\
\hline $\mathrm{DB}^{\mathrm{a}}$ & $.12 *$ & $.10^{*}$ & .10 & 1.00 & & & & & & & & & & & \\
\hline $\mathrm{DB}^{\mathrm{b}}$ & .04 & $.39 * *$ & $.31 * *$ & -.05 & 1.00 & & & & & & & & & & \\
\hline $\mathrm{DB}^{\mathrm{c}}$ & .05 & $.50 * *$ & $.57 * *$ & -.04 & $.53 * *$ & 1.00 & & & & & & & & & \\
\hline $\mathrm{AB}^{\mathrm{a}}$ & $-.43 * *$ & -.03 & $-.11 *$ & $-.12 *$ & .00 & -.04 & 1.00 & & & & & & & & \\
\hline $\mathrm{AB}^{\mathrm{b}}$ & -.09 & $-.24 * *$ & $-.21 * *$ & -.05 & .03 & -.00 & $.12 *$ & 1.00 & & & & & & & \\
\hline $\mathrm{AB}^{\mathrm{c}}$ & .02 & $-.24 * *$ & $-.28 * *$ & .00 & .06 & -.06 & .07 & $.64 * *$ & 1.00 & & & & & & \\
\hline $\mathrm{SS}^{\mathrm{a}}$ & $.21 * *$ & .01 & .03 & .04 & -.03 & -.05 & $.32 * *$ & -.00 & .02 & 1.00 & & & & & \\
\hline $\mathrm{SS}^{\mathrm{b}}$ & -.01 & $.42 * *$ & $.46^{* *}$ & .01 & $.36 * *$ & $.41 * *$ & .04 & $.42 * *$ & $.22 * *$ & .05 & 1.00 & & & & \\
\hline $\mathrm{SS}^{\mathrm{c}}$ & .03 & $.40 * *$ & $.44 * *$ & .04 & $.30 * *$ & $.43 * *$ & .06 & $.28 * *$ & $.39 * *$ & .08 & $.61 * *$ & 1.00 & & & \\
\hline $\mathrm{PF}^{\mathrm{a}}$ & $.61 * *$ & .04 & .01 & .00 & .06 & .03 & $-.47 * *$ & $-.13 *$ & -.02 & $.20 * *$ & .08 & .01 & 1.00 & & \\
\hline $\mathrm{PF}^{\mathrm{b}}$ & .02 & $.79 * *$ & $.76^{* *}$ & -.05 & $.44 * *$ & $.55^{* *}$ & -.02 & $-.23 * *$ & $-.23 * *$ & .01 & $.45^{* *}$ & $.46^{* *}$ & .00 & 1.00 & \\
\hline $\mathrm{PF}^{\mathrm{c}}$ & -.04 & $.73 * *$ & $.78 * *$ & $.12 *$ & $.32 * *$ & $.57 * *$ & .01 & $-.15 * *$ & $-.25 * *$ & .03 & $.47 * *$ & $.49 * *$ & .02 & $.76^{* *}$ & 1.00 \\
\hline$A V E$ & .58 & .76 & .76 & .54 & .55 & .55 & .54 & .51 & .51 & .53 & .57 & .66 & .66 & .76 & .83 \\
\hline Mean & 3.12 & 2.82 & 2.93 & 2.18 & 2.50 & 2.70 & 1.51 & 1.82 & 1.85 & 2.41 & 2.41 & 2.51 & 3.24 & 2.91 & 2.94 \\
\hline$S D$ & .70 & 1.17 & 1.21 & .70 & .93 & 1.01 & .94 & 1.16 & 1.27 & .63 & .85 & .89 & .82 & 1.15 & 1.29 \\
\hline$C R$ & .81 & .91 & .91 & .78 & .79 & .78 & .78 & .76 & .76 & .78 & .80 & .86 & .86 & .91 & .94 \\
\hline Cronbach $\alpha$ & .81 & .90 & .90 & .77 & .78 & .78 & .77 & .75 & .75 & .76 & .80 & .85 & .85 & .90 & .93 \\
\hline
\end{tabular}

Note. TI, training and instruction; DB, democratic behaviour; AB, autocratic behavior; SS, social support; PF, positive feedback; CR, Composite reliability -

${ }^{\mathrm{a}}=$ self-perception; ${ }^{\mathrm{b}}=$ perception ${ }^{\mathrm{c}}=$ preference

$* p<0.05, * * p<0.01$ 
Table 4

Factor loadings, composite reliability (CR), and average variance extracted (AVE) for each 15-item LSS short version of the cross-validation sample

\begin{tabular}{|c|c|c|c|c|c|c|c|c|c|}
\hline \multirow[t]{2}{*}{ Subscales/Items } & \multicolumn{3}{|c|}{$\begin{array}{l}\text { Coaches self-perceived behavior } \\
\qquad(n=351)\end{array}$} & \multicolumn{3}{|c|}{$\begin{array}{l}\text { Athletes perceived coach behavior } \\
\qquad(n=817)\end{array}$} & \multicolumn{3}{|c|}{$\begin{array}{l}\text { Athletes preferred coach behavior } \\
\qquad(n=817)\end{array}$} \\
\hline & Loadings & $\mathrm{CR}$ & AVE & Loadings & $\mathrm{CR}$ & AVE & Loadings & $\mathrm{CR}$ & AVE \\
\hline Training and Instruction & & 0.76 & 0.51 & & 0.86 & 0.67 & & 0.81 & 0.59 \\
\hline TI1 & 0.68 & & & 0.83 & & & 0.75 & & \\
\hline TI2 & 0.83 & & & 0.84 & & & 0.74 & & \\
\hline $\mathrm{TI} 3$ & 0.61 & & & 0.78 & & & 0.81 & & \\
\hline Democratic Behavior & & 0.87 & 0.68 & & 0.82 & 0.62 & & 0.79 & 0.56 \\
\hline DB1 & 0.85 & & & 0.91 & & & 0.78 & & \\
\hline DB2 & 0.81 & & & 0.68 & (8) & & 0.61 & & \\
\hline DB3 & 0.81 & & & 0.74 & & & 0.83 & & \\
\hline Autocratic Behavior & & 0.73 & 0.48 & & 0.75 & 0.52 & & 0.82 & 0.62 \\
\hline $\mathrm{AB} 1$ & 0.72 & & & 0.55 & & & 0.87 & & \\
\hline AB2 & 0.71 & & & 0.85 & & & 0.78 & & \\
\hline AB3 & 0.64 & & & 0.72 & & & 0.68 & & \\
\hline Social Support & & 0.85 & 0.66 & & 0.82 & 0.61 & & 0.82 & 0.60 \\
\hline SS1 & 0.79 & & & 0.83 & & & 0.68 & & \\
\hline $\mathrm{SS} 2$ & 0.77 & & & 0.86 & & & 0.77 & & \\
\hline $\mathrm{SS} 3$ & 0.86 & & & 0.62 & & & 0.87 & & \\
\hline Positive Feedback & & 0.75 & 0.50 & & 0.80 & 0.57 & & 0.86 & 0.67 \\
\hline PF1 & 0.61 & & & 0.81 & & & 0.82 & & \\
\hline PF2 & 0.78 & & & 0.69 & & & 0.77 & & \\
\hline PF3 & 0.72 & & & 0.77 & & & 0.86 & & \\
\hline
\end{tabular}


Table 5

Means, standard deviations, reliability, squared correlations, convergent and discriminant validity among LSS-15 and ASQ subscales ( $n=246)$.

\begin{tabular}{|c|c|c|c|c|c|c|c|c|c|c|c|c|c|c|}
\hline & \multicolumn{10}{|c|}{ LSS-15 subscales } & \multicolumn{4}{|c|}{ Athlete Satisfaction subscales } \\
\hline & $\mathrm{TI}^{\mathrm{a}}$ & $\mathrm{TI}^{\mathrm{b}}$ & $\mathrm{DB}^{\mathrm{a}}$ & $\mathrm{DB}^{\mathrm{b}}$ & $\mathrm{AB}^{\mathrm{a}}$ & $\mathrm{AB}^{\mathrm{b}}$ & $\mathrm{SS}^{\mathrm{a}}$ & $\mathrm{SS}^{\mathrm{b}}$ & $\mathrm{PF}^{\mathrm{a}}$ & $\mathrm{PF}^{\mathrm{b}}$ & IP & $\mathrm{TP}$ & T\&I & PT \\
\hline $\mathrm{TI}^{\mathrm{a}}$ & 1.00 & & & & & & & & & & & & & \\
\hline $\mathrm{TI}^{\mathrm{b}}$ & .11 & 1.00 & & & & & & & & & & & & \\
\hline $\mathrm{DB}^{\mathrm{a}}$ & $.15^{*}$ & .02 & 1.00 & & & & & & & & & & & \\
\hline $\mathrm{DB}^{\mathrm{b}}$ & .01 & $.12 *$ & $.30 * *$ & 1.00 & & & & & & & & & & \\
\hline $\mathrm{AB}^{\mathrm{a}}$ & $-.26^{*}$ & -.06 & $-.18^{*}$ & $-.14^{*}$ & 1.00 & & & & & & & & & \\
\hline $\mathrm{AB}^{\mathrm{b}}$ & -.05 & $-.17 *$ & -.01 & $.58 * *$ & $.42 * *$ & 1.00 & & & & & & & & \\
\hline $\mathrm{SS}^{\mathrm{a}}$ & $.16^{*}$ & -.01 & $.14^{*}$ & .01 & $-.18 *$ & -.01 & 1.00 & & & & & & & \\
\hline $\mathrm{SS}^{\mathrm{b}}$ & .08 & $-.26 * *$ & .02 & $.33 *$ & $-.16^{*}$ & $.14^{*}$ & $.39 * *$ & 1.00 & & & & & & \\
\hline $\mathrm{PF}^{\mathrm{a}}$ & $.25^{* *}$ & .03 & $.34 * *$ & .02 & $-.32 * *$ & -.08 & $.55^{* *}$ & $.23 * *$ & 1.00 & & & & & \\
\hline $\mathrm{PF}^{\mathrm{b}}$ & .08 & $.26 * *$ & .02 & -.01 & -.01 & $-.35 * *$ & .02 & $.35 * *$ & $.12 *$ & 1.00 & & & & \\
\hline IP & $.35 * *$ & $.41 * *$ & .01 & .08 & $-.12 *$ & $-.38 * *$ & $.43 * *$ & $21 * *$ & .01 & $.36 * *$ & 1.00 & & & \\
\hline $\mathrm{TP}$ & .02 & .03 & .06 & .01 & $-.40 * *$ & $-.31 * *$ & $.16^{*}$ & $.41 * *$ & .02 & $.48^{* *}$ & $.56^{* *}$ & 1.00 & & \\
\hline T\&I & $.31 * *$ & $.25^{* *}$ & $-.24 * *$ & .06 & -.01 & -.02 & $.15^{*}$ & $18^{*}$ & $.26^{* *}$ & .06 & $.38 * *$ & $.68^{* *}$ & 1.00 & \\
\hline PT & $.28 * *$ & $.15^{*}$ & $.32 * *$ & $.43 * *$ & $-.16^{*}$ & $-.42 * *$ & $.36 * *$ & $.28 * *$ & .02 & $.42 * *$ & $.43 * *$ & $.53 * *$ & $.42 * *$ & 1.00 \\
\hline$A V E$ & .54 & .63 & .56 & .60 & .68 & .55 & .66 & .62 & .71 & .55 & .59 & .71 & .66 & .66 \\
\hline$M$ & 4.79 & 4.09 & 3.88 & 3.21 & 2.02 & 2.95 & 3.71 & 3.19 & 4.32 & 3.91 & 4.80 & 4.56 & 4.61 & 4.86 \\
\hline$D P$ & .76 & .62 & .62 & .82 & .52 & .88 & .64 & .76 & .52 & .76 & .88 & .92 & 1.02 & 1.18 \\
\hline$C R$ & .78 & .84 & .78 & .83 & .72 & .76 & .85 & .85 & .89 & .78 & .82 & .89 & .88 & .91 \\
\hline Cronbach $\alpha$ & .77 & .80 & .76 & .81 & .68 & .76 & .83 & .85 & .88 & .79 & .79 & .89 & .85 & .89 \\
\hline
\end{tabular}

Note. TI, training and instruction; DB, democratic behaviour; $\mathrm{AB}$, autocratic behavior; SS, social support; PF, positive feedback; IP = individual performance; $\mathrm{TP}=$ team performance; $\mathrm{T} \& \mathrm{I}=$ satisfaction with training and instruction; $\mathrm{PT}=$ personal treatment; AVE = variance average extracted; $M$ $=$ mean $S D=$ standard deviation $; \mathrm{CR}=$ Composite reliability $;{ }^{\mathrm{a}}=$ preference $;{ }^{\mathrm{b}}=$ perceived

$* p<.05$, ** $p<.01$. 


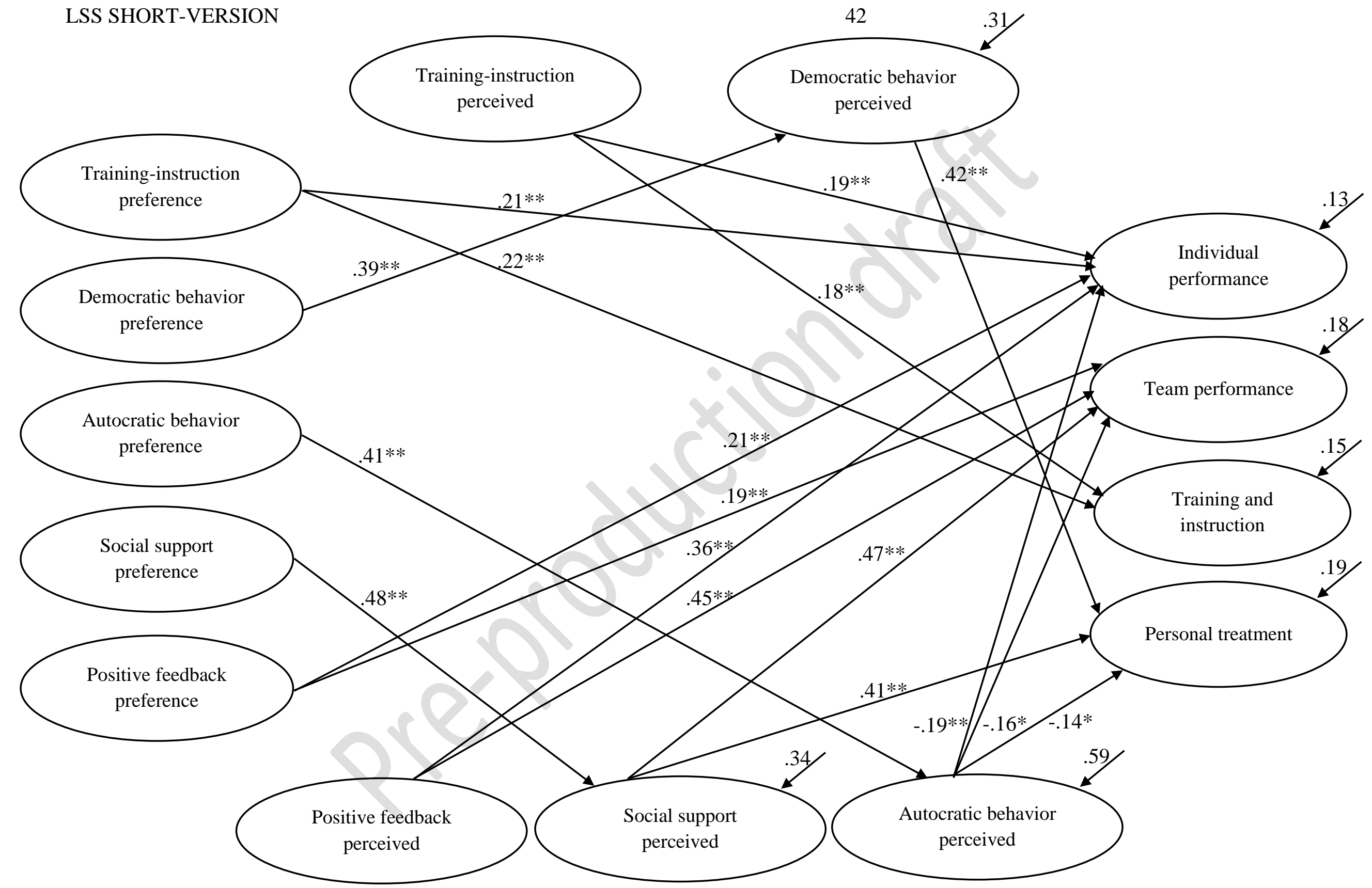

Figure 1. Structural model of relationships between preferences and perceptions of leader behaviors with athletes' satisfaction. Note. *p $<.05, * * p<.01$. All variances were significant $(p<.001)$. For visual simplicity, non-significant relationships $(p>.05)$ were not presented $(n=246)$. 